\title{
The Role of Decorative Sculpture in the Urban Environment and Its Connection with the Architecture of the Tashkent City
}

\author{
Kamila Khikmatullaeva \\ The State Museum of Afts of Uzbekistan, Tashkent, Uzbekistan
}

\begin{abstract}
The article is dedicated to the aesthetic organization of the urban environment, interaction of architecture in line with the decorative sculpture and reflection of the above mentioned on the urban-scale. The given interaction is inclined to play significant role in terms of countering urgent issues and addressing contemporary concerns of society. The investigation is dealt with the study of decorative sculpture in the urban environment and its connections with the urban architecture.
\end{abstract}

Keywords: architecture, decorative sculpture, urban environment, art, artistic design, monumental sculpture

\section{Introduction}

The interaction of decorative sculpture with the architecture of industrial production is one of the most relevant and least developed sections of the theory and history of art history.

Technical gains and scientific progress have in fact turned out to be a tragedy for the individual—a lack of attention to the environment, a loss in it of spirituality, artistic diversity, harmony, necessary for a person. One of the most important reasons, from our point of view, is the absence in the new residential areas of even hints of a genuine link between architecture and the visual arts. It is art that aesthetizes the environment and human life, appeals to his thinking and supports in him a sense of belonging to what we call—world culture. This role of art can not be denied even today.

For a long time humanity used elements of painting and sculpture in order to enrich the architectural expressiveness of buildings. The history of ancient civilizations of Asia and Egypt proves that art associated with construction is the oldest kind of fine arts. Relation to the modern interior as to the dynamic integrity perceived in time, acquires special significance in the harmonization of the ensemble of internal spaces (Uvarov V.D., 2016, pp. 4-7).

The national style of architecture, devoid of haughty monumentality, is being revived by folk artists. Paired ensembles of the Mourning and Lucky Mothers, Chimes, fountains and domes were born from Uzbek concepts of kosh and zhuft, opening the rights of citizenship to the direct aspirations of the national mentality. Not copying, but own interpretation of classics become important (Askarov Sh. 2012, p. 194).

The purpose of our research was to determine the role of decorative sculpture in the urban environment and its relationship with the architecture of the city, to study the historical past of decorative urban planning in 
Uzbekistan.

\section{The Urgency of the Problem}

The emphasis on this direction is based on the fact that the pressing problems facing architects and artists of modern Tashkent can not be resolved, firstly, outside of strong and strong ties with the high traditions of the city's city-forming culture, and secondly, beyond experience of modern world civilization.

This problem has an obvious historical parallel, especially significant for Uzbekistan, in which art has always been a natural part of his life, had his practical and ideological functions, created the unity and uniqueness of a particular environment. Today, with astonishment and ecstasy, we look at the historically established center of Tashkent, its ensembles and city highways, streets and lanes that human activity was able to transform without disturbing its original harmonious structure. We admire the perfect taste that the architects of previous generations possessed, allowing them to enter with an amazing tact in the architectural environment of works of art. The imaginative language of a historically developed city is not conceivable today without a compositional community of architecture with monumental plastics, sculptural decor.

The aesthetically rich spaces of the old city with works of art highlight his emotional priority over the new building, the perception of which is complicated by the universal universality and "typical features" of mass industrial housing construction. At the same time, the urban environment is not a continuously developing system in which monumental and monumental and decorative art has always been a leading place.

Today we are aware of the spiritual hunger in the environment that we inhabit, and, the sharper, the denser we are surrounded by massive buildings. It is forgetfulness of traditions for many decades, settled in our amazing city, faceless and monotonous, stereotyped and monotonous.

The need to not only support but also develop on a new basis the architectural and plastic culture of Uzbekistan in the process of its territorial growth determines the formulation of the problem of this study. It consists in the following: is it possible to continue the accumulation of spiritual and aesthetic values that enrich the memory of the city with worthy works of their days, multiplying it with modern solutions? Can modern art, in particular, monumental and decorative sculpture, help resolve this issue?

We must not forget that sculpture itself arises in a different spiritual and social climate that characterizes the present stage of development of our society. All this should serve as an impetus to the appearance of a species and genre variety of monumental and decorative sculpture. Her artistic and plastic variety.

The second main direction of the problem development is the study of the historical domestic experience, as well as the modern domestic and world practice of including sculpture in the urban development on the basis of the last three decades associated with the intensive process of unification and typification of construction.

\section{Research Results}

High spatial and plastic culture of the urban environment of Uzbekistan represents a unique unity of all levels of its components-from the architectural ensemble to the streets, courtyards and local areas. This makes it possible to study it as an existing whole at the given moment. The architectural and plastic culture of the city allows us to examine our past, assess the present, and presuppose the future. In the modern look of Tashkent, the handwriting of several epochs is seen, the evolution of styles is clearly traced. The development of urban 
sculpture, as one of the components of the image of the city, has always been in indissoluble interaction with architecture, primarily with other arts, as well as with culture in general, understood by us as a set of spiritual values. City sculpture reflected every stage of culture, leading to the creation of new trends in art and architecture. A significant role was played by sculpture in the addition of the artistic image of the city, not only expanding its saturation, but also revealing, emphasizing the peculiarities of Tashkent proper, the correspondence between architecture and the natural environment.

However, the complex changes in the creative direction that took place in Soviet architecture, the course toward mastering the architectural heritage of the past, which at that time became decisive, changed the attitude towards the genre of monumental and decorative plastics. Pomposity and illustrations begin to predominate in its dominant style. Sculpture is often envisaged as a "detail” ("plastic accent”), often beautifully drawn, but not beyond the framework of stucco craftsmanship. Individual compositions were limited to static images in the form of statues. The emotional and aesthetic impact of such solutions was reduced to a minimum.

Thus, from the aesthetic sphere of the spiritual saturation of the city, such concepts as decorativeness, symbolic generalization, metaphorical ideas go away, cultural orientations so characteristic of the old city are lost.

Touching on various aspects of the artistic process of the Soviet period, it is necessary to distinguish between its objective and subjective sides. It does not require proof that a great deal of creative success in the monumental plastic of those years was contributed by the high professional literacy, talent and skill of many sculptors, whose aspirations were constrained by dogmatic norms and opportunistic prescriptions of the era. Time dominated those years over the artists.

But the general adherence to certain plastic traditions in the town-planning practice of Uzbekistan, the more the idea of the context of the urban environment and the timeless significance of the monuments of culture and art in the post-war decade testified that the aesthetic ideal of the city, laid down in Uzbekistan since its inception, was lost was.

Turning to the works of the genre of monumental and decorative sculpture, which is in direct interaction with the architecture of public buildings, first of all, it should be noted such as bas-reliefs on the building of the Alisher Navai Theater, a monumental composition in the metro building, etc. Monumentality, severity, simplicity in the interpretation of facades all listed architectural structures. I want to note that behind the modest volumes of public buildings one can not fail to see the great analytical work that was done by the architects in those years. Despite the harsh conditions in which they worked, it was during the design and construction of public buildings that architects and artists did not stop thinking about architecture, the age-old principle of which was the unification of the arts.

The general processes of restructuring Soviet architecture in the second half of the 1950s and the early 1960s, connected with the development of industrial housing construction and influencing the change in the architectural and spatial means of composition of the residential ensemble, simultaneously changed the attitude towards the community of fine arts and housing architecture. The heightened interest in the functional and utilitarian tasks of mass standard housing construction pushed aside the aesthetic problems in general and the problems of art synthesis, in particular. On the agenda were requirements of a material and technical nature, the problems of prefabricated housing construction technology, which had an impact on the figurative and plastic characteristic of 
a typical building and obscured artistic problems.

Developing in the mainstream of the academic direction of the sculptural school of sculpting easelism has largely changed the plastic system of monumental art, has introduced literacy as the most truthful measure of the embodiment of the image. The result of the enthusiasm of easel painting was the active use in the urban environment of a special genre form —a portrait monument-bust. Numerous portraits of scientists, poets, writers, built on accurate mapping of nature, careful study of plastic masses, performed skillfully, but dryly and detached, at the same time acquire new features corresponding to their existence in the midst of the masses, among them —a special proximity to people.

The prerequisite for the appearance of innovative forms of decorating buildings with sculptural plastics was the desire in the late XIX — early XX century to search for new architectural styles. Modern, neoclassicism raised the genre of architectural and plastic decor to the expression of genuine self-worth. The variety, unrepeatable techniques were deepened by the search for refined refined lines and decorative motifs, the desire-in the first case—-to resolutely abandon the traditional schemes, in the second—-to re-think them over again.

\section{Conclusion}

A short excursion into the historical past of Uzbekistan, which allowed us to give a brief assessment of its main stages from the perspective of today's problems of the urban environment, shows that the monumental and monumental and decorative sculpture is an integral component entering the cultural and historical context of the city.

The historically developed urban environment demonstrates the ramified hierarchy of artistic elements present at all levels of the three-dimensional and architectural-planning structure of the city-from a separately standing architectural volume, a house site, streets and squares of city-wide importance to the highest stage of town-planning art - the ensemble.

The image of the city is formed primarily under the influence of compositional building links with the natural and geographical conditions of the environment. The spatial structure of industrial zones, recreational areas and other areas creates a unique image of a particular city.

Characteristic, memorable structures that create the silhouette of the city and make up the basis of its spatial, compositional structure.

First of all, the image of the city is formed by the volume-planning structure of residential areas in conjunction with certain public areas, including prestigious buildings (public, administrative, etc.) parks, industrial complexes. Then—natural conditions, relief, greenery, water. Developing in Tashkent, the decorative relief and park sculpture are characterized by sincerity, unpretentious decorative motifs.

In the new districts of old cities and in modern cities, the most significant role is played by the combination of the city's main thoroughfares with squares that are public centers in urban areas. The role of such centers should be emphasized by the greatest concentration of works of monumental and decorative art on them and buildings of an original architecture.

Conclusions: The possibilities of sculpture are great—it can emphasize city coordinates, serve as a reference point or composition dominant, allocate individual spaces between them, adjust their scale characteristics, and fix visual connections. Thus, a monumental and decorative sculpture bears a town-building function. 
It is necessary not only to support, but also to develop on a new basis the architectural and plastic culture of Uzbekistan in the process of its territorial growth.

\section{References}

Uvarov, V. D. (2016). The problem of aesthetic organization of the object-spatial environment of the interior. Decorative art and the subject-spatial environment. Moscow: "MSTU named after A.N. Kosygin”

Askarov, Sh. (2012). Architecture of Uzbekistan of the CIS countries. Tashkent: "Sanat”. 